\title{
A New Insight into Design Approach with Focus to Architect-Client Relationship
}

\author{
Nima Norouzi ${ }^{1,2}$, Maryam Shabak ${ }^{1,3}$, Mohamed Rashid Bin Embi ${ }^{1} \&$ Tareef Hayat Khan ${ }^{1}$ \\ ${ }^{1}$ Department of Architecture, Faculty of Built Environment, University Technology Malaysia, Johor Bahru, \\ Johor, Malaysia \\ ${ }^{2}$ Islamic Azad University, Jouybar Branch, Department of Architecture, Jouybar, Iran \\ ${ }^{3}$ Islamic Azad University, Noor Branch, Department of Architecture, Noor, Iran \\ Correspondence: Nima Norouzi, Department of architecture, faculty of built environment, university technology \\ Malaysia, 81310, Johor Bahru, Johor, Malaysia. E-mail: nimanorouzi@outlook.com
}

\author{
Received: October 1, 2014 Accepted: October 24, 2014 Online Published: February 12, 2015 \\ doi:10.5539/ass.v11n5p108 URL: http://dx.doi.org/10.5539/ass.v11n5p108
}

\begin{abstract}
Many studies stress cooperation between architects and clients in which knowledge and experiences are shared in order to reach synergy. Thus, a process approach is required to make the latent knowledge and intention of the client explicit, efficiently connecting him/her to the architect. However, little attention has been given to socio-technical features of this relationship within architectural design process. This study aims to present an approach with collaborative, communicative and innovative features, which develop client involvement, information sharing and design-supporting tools within architectural design process. A literature survey has been conducted to investigate the characteristics of the communication process, architectural design process, design-supporting tools and means, method and concept of virtualization in design and communication. Finally, this study concluded by integrating the concept of virtualization and virtual reality tools into communication and design process. A new design approach will be generated, which will satisfy both architect and client, as well as design outcomes.
\end{abstract}

Keywords: architectural design process, communication process, design supporting tools, user participation, virtualization, virtual reality

\section{Introduction}

Communication is the principle concern of architecture. Generally, the opinions and beliefs of architects are developed based on their accomplishments in professional exercises, which must be presented to the clients. According to (Bruggen, 1998) architects do "whatever they thought would communicate their concept for the building." Architects mostly have communicated with clients Face-To-Face (FTF) and more recently in the form of verbal and visual representations. Modern advancements of information and communication technologies developed the means and methods of communicating and visualizing design representations. In addition, the expanding complexity of building design and the growing need of efficient participation of clients are challenging issues, which make it essential to establish a new perspective of design approach with support of computer-mediated tools to help the architect and client achieve synergy in the design process.

To achieve the satisfaction of the architect and client, it is vital in the new design approach to consider the nature and current situation of their relationship while communication plays a pivotal role to establish and maintain this relationship within all design stages. In this case, the way of communicating and using communication artefacts into architectural design processes to facilitate design information exchange enhances the capability of architect and client to convey information accurately in a proper manner. Consequently, the satisfaction of two parties with the design process will increase as well as the quality of the design outcome (M Shabak, Norouzi, \& Khan, 2013), (Mayam Shabak, Norouzi, Abdullah, \& Khan, 2014). This research is concerned with the study of the relationship between the architect and client with a focus on facilitating user involvement and utilizing interface to the design process to introduce a new insight to the design approach by identifying socio-technical characteristics of a successful relationship. 


\section{Miscommunication between Architect and Client}

Poor communication can be expressed in at least three different ways: articulation, misunderstanding and conflict. Articulation is the ability to express information; misunderstanding implies separate interpretations of the same piece of information and conflict is defined as multi-perspective viewpoints and/or disagreements. These difficulties afflict both users and designers alike and occur within user and designer (Coughlan \& Macredie, 2002). The major type of categorized problems as determined by numerous studies in the design process is disconnection or miscommunication between architect and client and both with the design process. Miscommunication is defined as a failure to communicate adequately and properly and often results in confusion and frustration. A disproportionate number of defects in the architectural design can be traced to the inefficiency of communication between the architect and the client. The poor communication and inadequate specifications of architectural domain knowledge from the client has been implicated as a main obstacle to increasing the quality of the design itself and the satisfaction of the client simultaneously. Thus, defining the role of architect and client in the architectural building design as a communicative activity will reduce miscommunication as well as facilitate information exchange by clarifying design aspects.

\section{Architect and Client in Design Process}

Traditionally, architects perform architectural design practice in distinct positions (Gray \& Hughes, 2001) ranging from design specialist, to moving into the role of administrator, coordinator and manager of the design process. The design, as a social means, has a deeply complicated nature in which anticipated and inconstant interplays, interdependencies and interrelations between participants and with processes builds the physical environment (Cuff, 1992). In the new digital era, Architectural design projects are extremely complex, requiring the skills of many individuals from diverse backgrounds that need to be brought together as a well-organized unit Thus, the interaction of a sound professional and efficient communication system is essential to meet the client's requirements. The ability to deal with problems effectively and communicate decisions clearly with the client is fundamental skills of an architect. Appropriate relationship between client/owner and designer lead them to a proper architectural design project. Such relationships have been neglected in terms of a practical relationship between them. Insufficient consideration of the designer to the client's wishes and requirements will result in the client's dissatisfaction with the final design, leading to increased obstacles, which separate the two parties. The most significant design failures, which were classified by (Lyytinen \& Hirschheim, 1988), are concerned with interaction, expectation, and the process. Some of them such as lack of a systematic process for the client's involvement address a single issue (process) and some others address a combination of issues. The result is poor communication between design participants (process, interaction, expectation) and the lack of relevant knowledge or mutual understanding (interaction, expectation).

Expectation: The lack of commitment between the owner and the designer on goals and specifications has been the main hindrance to the quality of design and at the same time affected clients' satisfaction, As a result, conflict is inevitable (Al-Hammad \& Al-Hammad, 1996). A successful project depends on the extent to which a client's wishes and needs are considered and managed by the architect. Obviously, the marketplace is competitive and architects who do not respect the demands and needs of clients will be rejected.

Process: the term design stage mainly refers to the process from briefing to design construction. RIBA, 2007 defined the outline plan of work in a building project as consisting of five stages: preparation, design, pre-construction, construction and usage. In most cases, the design process is the interactive involvement of designers and clients in discussions of design requirements and solutions. The rapid development of science and technology changed the nature of traditional architectural processes as well as the flow of traditional design (Oxman, 2008). These days digital methodologies are enhancing distinct capacities to perform and generate processes that had not existed before in conventional, paper-based methods (Oxman, 2008). The prevailing tendency in the building sector is the inability to maintain pace with innovation in processes and technology, which is an important indication of the inefficiency of the design procedure (Egan, 1998). Therefore, regardless of this tendency, by focusing on the process-tools, a creative approach can be developed which can facilitate communication and interaction of participants and improve the control and management of processes (Ang, Wyatt, \& Hermans, 2001).

Interaction: Designers are often not aware of domain and knowledge in a social context. In contrast, they prefer technical and technological design aspects. Socially oriented approaches highlight the role of equal participation of user/client and designer in design collaborative action, which enables them joint decision making as well as ensuring the satisfaction of both parties. Boland, 1978 viewed the structure of interaction of participants in a design activity as problem solving or problem-finding. Mutual understanding between designer and client 
generates solutions leading to high-quality design outcomes and satisfactory implementation will be achieved in problem finding interaction process.

\section{Communication and Architectural Design}

The main key element that underlines the importance of communication in the architectural design process is its ability to change, which has moved away from a focus on the end-user to user-centered design process and clients are more encouraged to participate in the design process in collaboration with the architect. Therefore, the study on the relationship between the role of architect and client and their expectations in both architectural design and communication process (Norouzi, Shabak, Embi, \& Khan, 2014) helps to determine the criteria of incorporating process, resulting in a successful design outcome. However, the association between the design process and communication is rarely explained in depth and the arguments that surround intention and interpretation have often escaped critical analysis. Prior to establishing the concept of communication in the architectural design process, a coherent understanding of what communication is and what it involves should be determined.

Feelings, opinions, mutual exchange of ideas, aspirations and the goal of individuals are facts and issues which involve communication (Olusegun, 2008). The main concerns of communication are not just possessing this information; the information should be understood, precisely evaluated by the person who received the information in the proper manner. Therefore, in order to share and explain the ideas to others communication strategies and necessary skills are required (Olusegun, 2008). Communication is the "process of exchange of information between the sender and receiver to equalize information on both sides" (Otter \& Prins, 2002). This definition is consistent with "sharing of meaning to reach a mutual understanding" (Otter \& Emmitt, 2008), and as a "cognitive and social process by which messages are transmitted, and meaning is generated" (Maier et al., 2008). The process of communication includes four components: sender, receiver, message and channel, which establish the communication model. Communication represents the extra-process role in dialogue between individuals. Architect sends the design solution as information to the client as a receiver. The suitable medium from paper drawing to digital modelling must encode the information in the form of some symbolic language, which makes it transmittable. Understanding these specific language games and to apply it in a meaningful and effective approach is the essential competency of an architect (Moum, 2008). The most common communication models have been presented to the linear model, interactive model and transactional model. Communication as a one-way process is called linear model where "the speaker and the listener just listen or speak (Lasswell, 1948) and (Weaver, 1949). In Interactive communication "both the speaker and the listener take turns to speak and listen to each other" (Schramm, 1955) and (Wood, 2014). Finally, in Transactional communication (Figure 1), both speaker and listener can send and receive messages simultaneously (Barnlund, 2009).

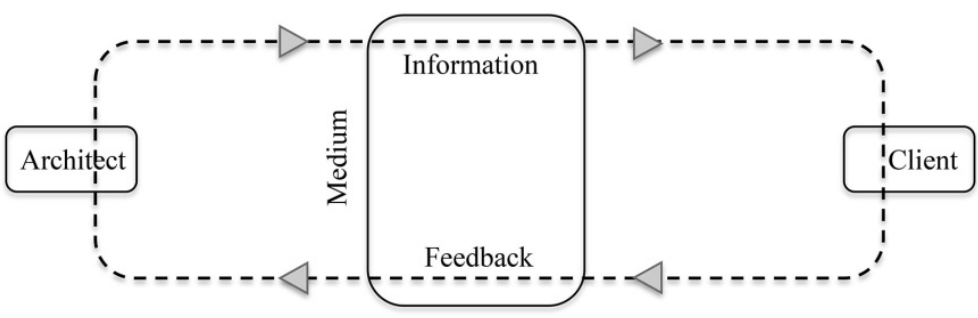

Figure 1. Diagram of communication between architect and client

A variety of means and models of communication have evolved over the long period from written to ComputerMediated Communication (CMC) such as phone, fax, email, and videoconference. Furthermore, looking back at these historical developments within the field of architecture, the culture of the architect and the client has improved as well as the form of relationship, from verbal communication to technical architectural drawings with Computer. Computer and digital technology came to the field of architecture and put into practice to produce 2D drawings, 3D volumetric, simulations, animation, or Virtualization in different stages of architectural design. The computer not only mediated in communication, but also tries to be applicable in the architectural design process (Gabriel \& Maher, 2002).

\section{Virtualization and Architectural Practice}

In the near future it is expected that Virtual Reality (VR) will produce a great leap forward in innovation of communication, architectural design and in the relevant fields (Briggs, 1996). Utilizing these artefacts to architectural design procedure remained the major problem, so significant changes are needed in the field of 
architecture and communication with respect to the social, cultural and technological aspects of communication and architectural design procedure.

\subsection{Virtualization of Interaction}

Nowadays, computers in addition to existing tools have rapidly secured a position as a unique medium within the architectural design process. In particular, Web development and the widespread use of the Internet has enabled the computer to become a medium for information processing, communication and interactive virtualization. The most commonly utilized hi-tech mediums in the field of architecture and communication are Computer-Aided Design (CAD), Information Communication Technology (ICT) and Virtual Reality (VR) technology. The participants within the architectural design process acknowledge ICT as a medium to access, exchange and retrieve data design electronically in digital form. It supports designers to establish and develop design ideas interactively (Lawson \& Loke, 1997). Using VR technology as a system of design visualization gives the participant better operational vision about the design solution during the architectural design process (Frost $\&$ Warren, 2000). In comparison to the using more symbolic and abstracted design information representations, using VR simulation reduces the misunderstanding between individuals in design practice. To embed VR technology into the design process required the support of social aspects and design strategies such as participatory design approach to generate an integrated process.

\subsection{Virtualization of Process}

Nowadays many societal processes, which traditionally have been carried out physically, are conducted electronically or virtually. The term "Virtual" is defined by the absence of physical interaction between objects and people or between people themselves (Overby, 2012). A process is determined as a set of activities to achieve a goal. By removing physical means of interaction in doing a series of activities, the virtual process is conceptualized (Fiol \& O'Connor, 2005). The virtual process is not only simulated but is also conducted (Overby, 2008). Most virtual processes are IT-based via virtualization mechanism (Overby, 2008). IT is a key factor for successful virtualization of processes. As this study defined, both communication and design are a set of process to achieve the objectives in which by integrating IT and digital technology into these processes the new design approach will be introduced in terms of virtualization.

\section{Utilization of Supportive Tools in Architectural Design}

The complexity of architectural design process is increasing; moreover, it is fragmented because of growing specialization in the building sector with its own strict regulations. Architectural design process has used a variety of Design-Supporting Tools (DST) with the potential of emerged new technologies available to designers today. DST facilitates performing the design process by utilizing various software and hardware, ranging from simple to complex as checklists to simulation software (Weytjens, Verdonck, \& Verbeeck, 2009). Unfortunately, there is no comprehensive classification of available DST based on frequency and spread of usage of tools in practice (Lam, 1999), (Mahdavi, 2003). Today's designers are practicing various advanced technologies such as Information Technology (IT), Information Communication Technology (ICT) in design activity, but they have insufficient ability and an effective method for utilizing artefacts into design procedure. As (Mahdavi, 2003) indicates, the aforementioned issue is problematic because new tools and applications have been developed without knowledge of users' needs (Weytjens et al., 2009).

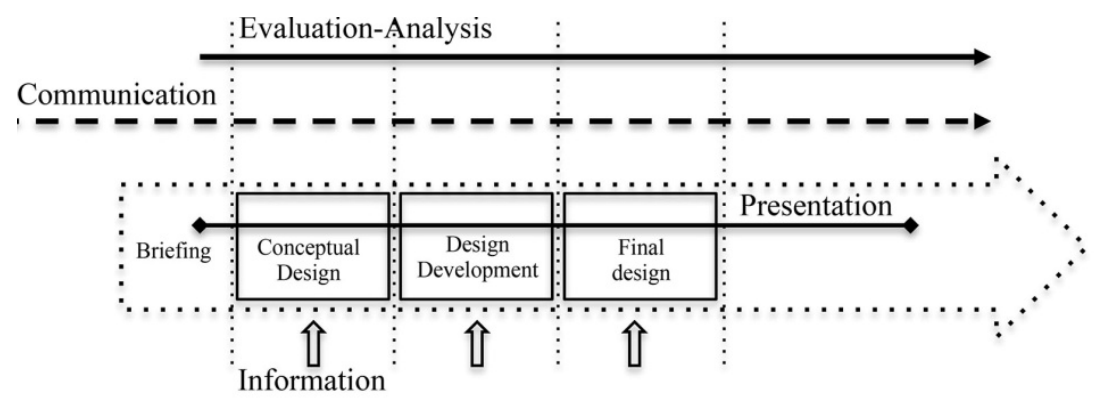

Figure 2. Overview of design process and design supportive tools (Weytjens et al., 2009)

To achieve a reliable tool assessment, subjective factors such as client feedback must be considered as criteria of selection tools. Indeed, certain moves and changes of architectural design tools should be adapted into architectural design process by improving communication culture. Foremost it requires comprehensive 
investigation of the current situation of architectural communication culture. In addition to the traditionally important considerations of cost, technological features and network externalities, other criteria such as the architect and clients' ability to implement technological solutions should be considered.

Weytjens et al., 2009 classified the supporting tools in the design process based on a comprehensive study and availability of tools to architects today. The different category of supporting tools as shown in (Figure 2) Influence the design process based on the nature of tools. The nature of tools can be as a knowledge base, analysis/evaluation base, and communication base or can be used for modeling, structuring, and for presentation. This diagram shows the design process as a linear process, but in reality, it is generally characterized as a cyclic and dynamic process with continuous feedback.(Bogers, Meel, \& Voordt, 2008)

Using advanced design tools with stronger visualization capability and effective communication medium empower designers to compile and change the implicit knowledge of clients to explicit and facilitate their collaboration within a design situation. Moreover, advanced IT/ICT/VR tools provide a virtual collaborative work environment where the architect and client can interact at dispersed locations and time zones. This study will focus on communication tools and design presentation tools based on this category as shown in (Figure 2).

\subsection{Time / Space Classified Communication Tools}

The widespread use of digital technology shifted from being design tools to being communication artefacts. Based on experiments on computer-aided communication in the early sixties, computers had potential to be as communication devices (Licklider \& Taylor, 1968). In these days, digital and Information Technology (IT) affected all aspects of everyday life especially in the filed of communication. Barney, 2004 defined this rapid technological advance in terms of "network society" as a phenomenon to illustrate the diffusion of information technology. The World Wide Web emerged with the invention of networking technology. This technology evolved the form of communication from telegraph and telephone to the Internet.

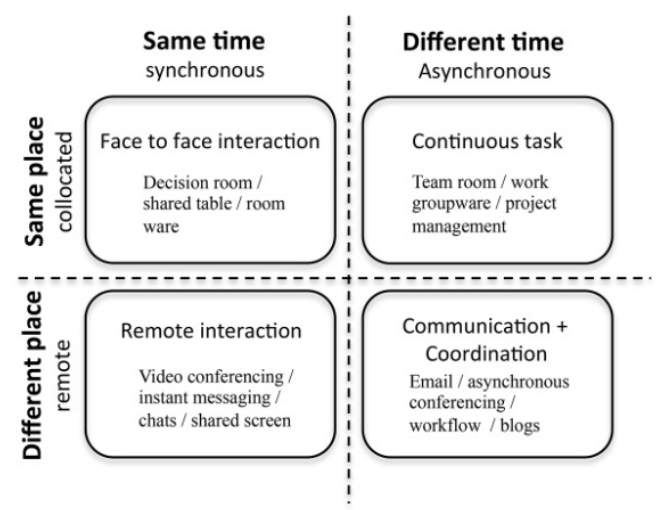

Figure 3. Time/Space classification of communication as a design supportive tools (Johansen, 1988)

Computer-mediated communications (CMC) are another term of networking communication technology. It encompasses the most popular computer based applications such as networks, electronic mail, electronic bulletin board and electronic conferencing. (Figure 3) Shows the wide spectrum of tools under the classification of time/space that have been used since the mid-nineties and which have continued to grow to the present day.

\subsection{Reality / Virtuality Classified Design Presentation Tools}

Terms and definition of Virtual Reality (VR) range from Reality to Virtuality. The term Mixed Realities is defined by Mailgram \& Colquhoun, 1999 within the continuum of Reality to Virtuality. The concept of reality and applications of reality technology are classified based on their applicability in design activities in terms of two dimensions: action-perception correlation and extended interaction with the real object.

For the first dimension, Aicher, 1994 advocates that in human-computer interaction designers/users need to have a strong connection of action and mental reflection through the use of tools. Aicher, 1994 defined action-perception correlation first as a perceived scene where the user can modify the final images and second by modifying the geometry and appearance as property of the real object. According to the design context, this concept provides opportunities for the user to practice the design tools through use and reflection (Bodker, 1989). 
In view of the second dimension, social interaction within the physical environment accelerates development of thoughts, ideas and cognitive activities. By this means, in the context of design activity, directly or indirectly, the level of user's ability to modify the real artifacts strongly depend on the degree of interaction of user/designer with the real artifact (Bodker, 1989), (Kaptelinin, 1996), (Schnabel, 2007).

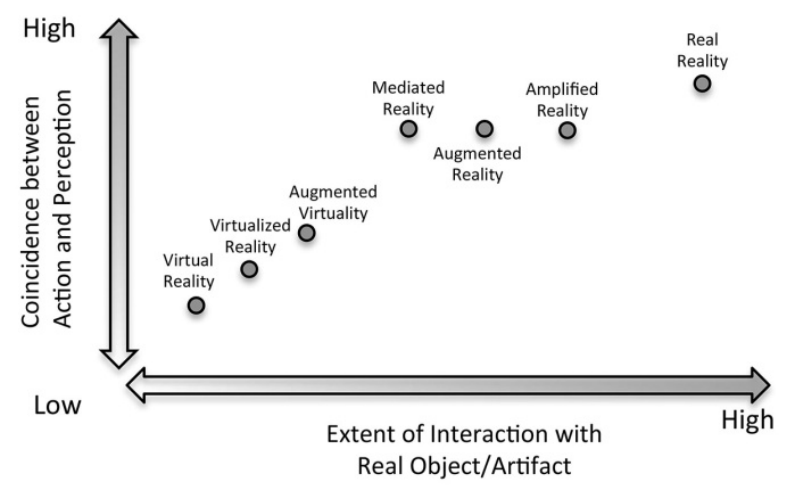

Figure 4. Classification of virtual reality tools as a design supportive tools (Schnabel, 2007)

According to the aforementioned dimensions, action-perception and interaction with real artifact, (Figure 4) presents the classification of realities concepts and technologies. Given this classification, there are six major realities from Real/physical Reality to Virtual Reality. This structured classification in the context of design accelerates the collaboration of participants and design comprehension, and addresses effective adoption issues for utilizing these concepts and technologies of realities within design activities. This classification helps designers to determine the terms of appropriate reality usage within design activities based on design characteristics in order to develop effective design practice (Schnabel, 2007).

\section{Facilitating User Involvement in Design Process}

There are many studies regarding the effective and efficient issues of participation of individuals in the various contexts of participatory design approach(Sarvarazadeh, Lamit, Norouzi, \& Shabak, 2013). Lee, 2008 declared that successful user involvement depends on the definition and appropriateness of facilitating characteristics. There are some facilitating means and approaches as follows:

1) Individuals need to establish a direct and explicit communication to reduce the chance of misunderstanding or misinterpretation on either side.

2) Individuals need to access realistic expectations and design information in order to have a reliable assessment of exact functioning and design experience under various circumstances.

3) Individuals need to be awarded and conscious about the consequences of design decisions to assess the reliable and efficient evaluation, which depends on comprehensive and transparent representation manner.

The most challenging stage, which indeed affects the final building, is process designs and the problem is lack of appropriate design language to engage the client in the design process. Ordinary drawings, images, and models are not suitable for dialogue with non-expert client because the client is neither able to understand drawings and models which are the words of this language, nor familiar with its structure. In this case, the characteristic of communication and its process should be studied in order to make it compatible with house design process. The studies show that when architect and user communicate verbally about a desired building the result is acceptable and the client is satisfied with participation in the design process, despite its outcome. Therefore, the architect should identify an effective approach in which the client is integrated into the design project to establish appropriate information and communication structure and conveying and chairing the meeting of client at all stages.

Successful user involvement can be achieved with consideration of facilitating characteristics by the concept of virtualization. Virtual interaction provides realistic design information in a highly accurate presentation, which enables individuals to experience design choices rather than imagine them (Biocca, 1995). Consequently the actual experience of design alternatives will enhance the reliability of design input information, which is the starting point of individual interaction within the design process. 


\subsection{Virtual and Physical Collaboration}

Collaboration is characterized as a process in which more than one individual contributes mutually to perform a shared aim. Such collaboration processes define physical collaboration in that participants are co-located to communicate face-to-face synchronously to reach a goal. In contrast with the condition that participants interact "virtually" at a diverse location asynchronously to realize a goal, the indicated collaboration process is determined to be a virtual process. Researchers define it in terms of dispersion on multiple dimensions, at a point across time or space (Fan, Sia, \& Zhao, 2012). Mostly virtual collaboration is IT based, which can implement strong collaboration technologies. Each characteristic of participants will additionally affect the realization of virtual collaboration (Handy, 1999) The level of trust and familiarity of participants to each other is defined as Participants Relationship, which is challenged with strengthening interpersonal relationships in virtual collaboration due to the inadequacy of social cues in electronic media (Yoo \& Alavi, 2004), (Aubert \& Kelsey, 2003), (Fan et al., 2012). By extension, participants experience, which is defined as the degree to which they are familiar with technology, will engage them appropriately with the technology and deliver better outcomes (Ann Majchrzak, 2000).

\section{Communication Process as a Design Process}

According to (Krenk, 2006), the building design process consists of the interaction of the participants managed within a dynamic and cyclic communication model. Effective methods and approaches could be implemented by bringing into account communicational aspects of building design process to improve the condition of the current situation. As described in the literature review about communication and its components which establish the communication model, the efforts of the architect and client to take up their positions in this process and share their knowledge and viewpoints of the design, resulting in communication which successfully assigns them roles in the architectural design process.

\subsection{Architectural Design Process}

Archer, 1968 in the book "The Structure of the Design Process", defined a design process as having four intertwined phases: "problem analysis, solution synthesis, evaluation and communication"(Figure 5) (Shen, 2011). Kalay, 2004 defined design in the recurring relationship of two paradigms: design as puzzle making and design as problem solving. In some cases design is viewed as exploring the situation, discovering the solution and presenting the new and unique one through synthesized process and sometimes viewed in attempting to create the solution. Lawson, 1997, describes the design process as "a negotiation between the problem and solution through the three activities of analysis, synthesis and evaluation," and (Schön, 1987) characterizes design practice as "a reflective dialogue between the designer and the design situation." (Moum, 2008). In the field of design education "Different students have different ways to learn, therefore, design process can vary from one student to another in the architectural studio" (Khan, 2012). The function of building design process crucially depended on significant factors as explicit communication, coordination and cooperation (Emmitt, 1999), (Fisher, 2000), (Krenk, 2006). The individuals involved in the design process demand new methods with the support of communication activity as a way to experiment with the process and improve the quality of design. Accordingly, an architectural design process may be understood as the process of making decisions about design alternatives with consideration of different aspects and components of building projects (Krenk, 2006). Meaningful participation of individuals is essential to shape the final design by extending the control over the decision-making in various stages of the design process.

Similarly (Cross, 1984) argues that customary and ordinary processes are inclined to form the basic model of analysis, synthesis and evaluation as segments. In this view analysis is determined as a stage of problem definition by gathering design requirements and synthesis as a stage of solution generation for performance of alternatives and finally evaluation as a stage of examining the accuracy of the final decision to meet the requirements. In parallel with the evolution of the problem and solution, (Cross, 2004), (Dorst, 2003) some researchers discussed the advantages of transition from the phased-based process to activity-based approach, where "continuous information gathering" has an important role to in support of this transition (Frens, 2008). John Restrepo, 2004 believed that the accessibility of existing and relevant design information are significant to support the activity-based strategies because designers in nature are solution-led in contrast to clients who are problem-led. Specially for producing concept design, provision to the design information and client's requirements lead the process to be intuitive rather than prescriptive while it needs sufficient structure to coordinate the individuals within the process to meet the objectives. In such a unique strategy, which allows the participants to access information freely, they feel they need to communicate to develop idea generation. In this way, they could have an accurate analysis and efficient solution to utilize in conceptual design process. 


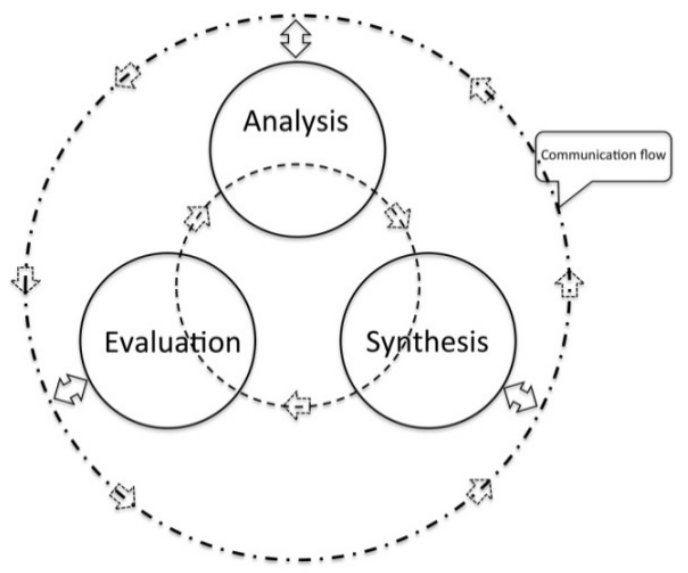

Figure 5. Model of collaborative design (Kalay, 2004)

Kalay, 2004 in "Architecture's New Media" signified the role of communication as a unique concept, which can link the various stages of the design process (Figure 5). He believes that building design is much too complex and subjective as a social act, which cannot be designed individually. To overcome the complexity requires active participation of specialist and the client within the design process; therefore, it needs coordination, communication and information sharing among stakeholders. This study, with regard to the important role of evaluation-analysis in the entire design process (Figure 2) viewed the design process as stages, which are shown in (Figure 5).

\subsection{Communication Process}

The Latin word "communis" which means common is the origin of the word of communication. Broadly, communication is defined as the process of transmitting information from one individual to another (Keyton, 2006). This definition underlines the exchange of ideas, thoughts and information, unless there is no communication (Cheney, 2004). Figure 1 reflects the main components and elements of the communication process. The sender sends the message (e.g. design information) through appropriate medium and channels to the others. The medium can vary from face-to-face communication to virtual communication. The receiver decodes the message into meaningful information and responds to the sender as feedback, which allows them to recognize the message with relevant meanings received and understood.

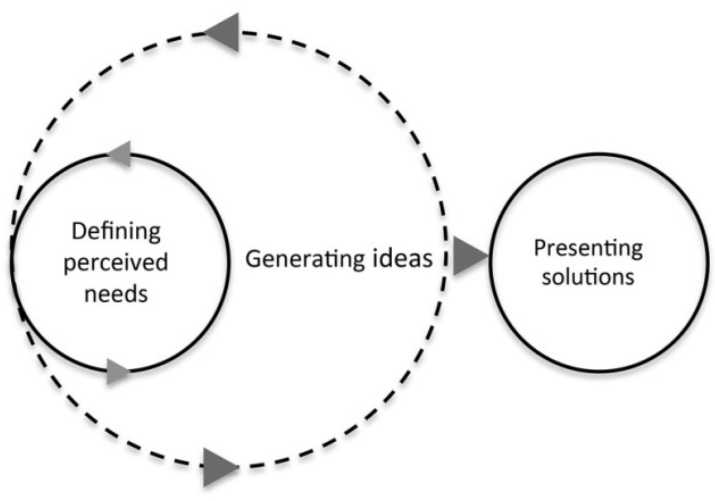

Figure 6. The three general communication activities identified in the communication process of design scenario

(Graell-Colas, 2009)

The architect and client who are involved and initial flow of the design brief and requirements ground within this relationship shape mostly the scenarios of the design project. The client who searches the solution to a design problem starts the communication process by expressing their needs and requirements. The design scenario is composed of perceived need, idea generation and design representation. During preliminary meetings, needs, as the architect and client perceive design problems. The architect then initiates the design opportunities and idea generation process with client involvement and finally presents a possible solution to the client. Generally, the design scenario as a communication process follows three communication activities (Figure 6): Communication 
interaction between client and architect to define the problem or perceived needs, to generate ideas and opportunities and to present the design solution or recommendation.

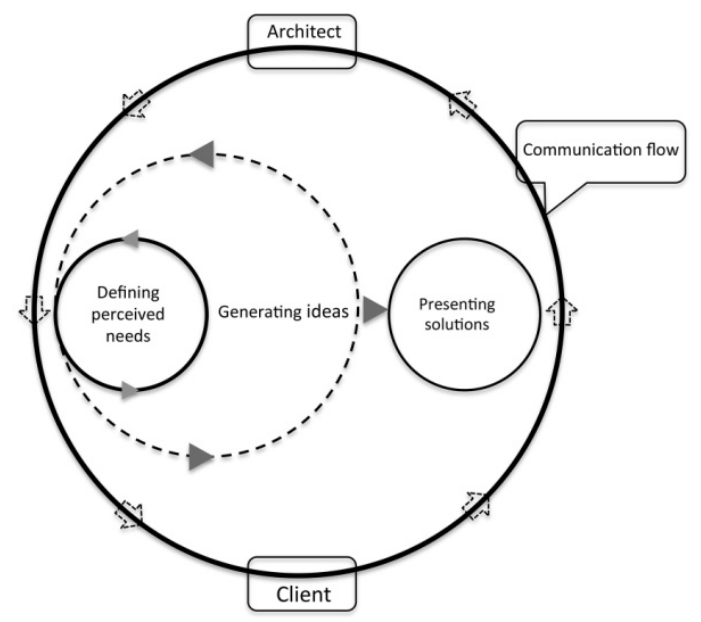

Figure 7. Diagram of successful model of communication flow in Architect-Client relationship (Graell-Colas, 2009)

\section{Discussion}

Without focusing on the characteristics of each stage of the design process, and in the view of communicative pattern, three main activities are an integral part of any design stage: analysis, synthesis and evaluation (Figure 5). The interconnection of these stages was viewed in the meaning of communicative activity. In addition, as shown in (Figure 7), this study viewed the design scenario as a communicative activity, which is based on three components: perceived need, idea generation and solution presentation. As presented in (Figure 8) a new design approach was deduced from the incorporation of the design process (Figure 5) and communication process (Figure 7). As shown the perceived need (expectation of client about the final design) in all analysis, a synthesis and evaluation stage is the core of this approach. The next level is idea generation in which problems are formulated and generated into solutions. Finally, solutions are evaluated in terms of meeting the objectives. In the new design approach, cyclic communicative exercise, which is established in the relationship between architect and client, is the core of this approach and extends to the last stage.

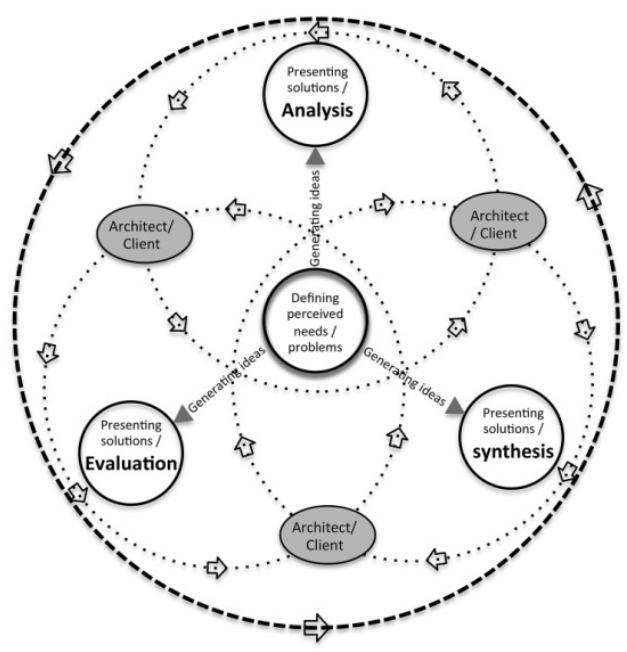

Figure 8. Diagram of proposed new design approach in this study

The Significant features of the new design approach are as follows:

Participative: in this approach the architect and client as shown in (Figure 8) participate in all design stages. As this approach is activity-based instead of phase-based, each activity within the design process is established and characterized in the form of communication and consultation pattern. The cooperation of architect and client establishes a shared understanding, which is significantly correlated to their responsibility within the design 
process. In addition, the success of each stage is achievable with the interactive and close engagement of architect and client in the needs analysis and problems on one hand and problem synthesis and generation of comprehensive ideas on the other.

Communicative: this approach is founded in communication pattern, in which communication flow is established in the dialogue of architect and client. From the perspective of architect-client relationship, the success of design approach when viewed as a social phenomenon is crucially dependent on their commitment in each stage of this scenario. Therefore, the quality of communication depends on transparency of perceived need, managing expectations and formulating them in a structured manner. Thus, the design outcome will be seriously affected by the quality of solution and accuracy of evaluation as an outcome of communication.

Innovative: in this design approach, in every stage, architect and client need to apply the tools based on the character and nature of each stage as classified in this study to achieve the objective (Figure 2) Moreover, in the final level, using appropriate tools will help them to present the solution in a way which is understandable and tangible to both parties. Tools have a prominent role in this approach and because of vast development in design and communication tools in the digital era, by adapting the technological changes into a design approach; an innovative and effective approach will be generated.

\section{Conclusions}

This study has shown that due to the social aspects of communicative action, integration of the communication concept into the design process motivated the participants to build a meaningful relationship. Consequently effective participation strengthened the relationship of both parties and will enhance their satisfaction in each stage of the design process. In this approach handling the right tools accelerated the design period and facilitated client involvement in the design process. Bringing virtualization principals, concepts and methods into communication and design process enhanced the efficiency of this approach. As shown in (Figure 5), with regard to the predominance of cycle of communication activity in the design process, the level of virtualization in communication and design process depends on advanced digital tools in the new design approach.

This study recommends investigating the relationship between the level of virtualization of communication and design process and level of satisfaction of architect and client with the design performance. It will be more practical by comparing the effect of using different tools in the design process on the level of virtualization and satisfaction of new design approach.

\section{Acknowledgements}

The authors sincerely acknowledge Research Management Center (RMC) of Universiti Teknologi Malaysia (UTM), and the Ministry of Education (MoE) of the Government of Malaysia, for the funding of the research through research grant No: 4L063, 4S104, and 07H37.

\section{References}

Aicher, O. (1994). Analogue and Digital: Writings on the Philosophy of Making. Wiley-vch.

Al-Hammad, A., \& Al-Hammad, I. (1996). Interface problems between building owners and designers. Journal of Performance, (August), 123-126. Retrieved from http://ascelibrary.org/doi/abs/10.1061/(ASCE)08873828(1996)10:3(123)

Ang, G., Wyatt, D., \& Hermans, M. (2001). A systematic approach to define client expectations of total building performance during the pre-design stage. Proceedings of the CIB 2001 ..., (April), 1-10.

Ann Majchrzak, R. E. R. (2000). BibSonomy: Publication: Technology Adaptation: The Case of a Computer-Supported Inter-Organizational Virtual Team.

Archer, L. B. (1968). The Structure of Design Processes (p. 211). Royal College of Art.

Aubert, B. A., \& Kelsey, B. L. (2003). Further Understanding of Trust and Performance in Virtual Teams. Small Group Research, 34(5), 575-618. http://dx.doi.org/10.1177/1046496403256011

Ayodele Elijah Olusegun, A. V. O. (2008). Communications in the building industry of nigeria - implications for clients (pp. 51-56).

Barney, D. (2004). The Network Society (p. 198). Polity.

Barnlund. (2009). Communication Theory (Google eBook) (p. 484). Transaction Publishers.

Bodker, S. (1989). A Human Activity Approach to User Interfaces. Human-Computer Interaction, 4(3), 171-195. http://dx.doi.org/10.1207/s15327051hci0403_1 
Bogers, T., Meel, J. J. Van, \& Voordt, T. J. M. Van Der. (2008). Architects about briefing: Recommendations to improve communication between clients and architects. Facilities, 26(3/4), 109-116. http://dx.doi.org/10.1108/02632770810849454

Boland, R. J. (1978). The Process and Product of System Design. Management Science, 24(9), 887-898. http://dx.doi.org/10.1287/mnsc.24.9.887

Briggs C. J. (1996). The promise of virtual reality. The futurist.

Cheney, G. (2004). Organizational communication in an age of globalization: issues, reflections, practices (p. 490). Waveland Press.

Coosje Van Bruggen, F. O. G. (1998). Frank O. Gehry: Guggenheim Museum Bilbao.

Coughlan, J., \& Macredie, R. (2002). Effective communication in requirements elicitation: a comparison of methodologies. Requirements Engineering, 7(2), 47-60. http://dx.doi.org/10.1007/s007660200004

Cross, N. (1984). Developments in design methodology (p. 357). Wiley.

Cross, N. (2004, September 1). Expertise in design: An overview. Design Studies.

Cuff, D. (1992). Architecture: The Story of Practice (p. 306). MIT Press.

Den Otter, A. F., \& Prins, M. (2002). Architectural design management within the digital design team. Engineering Construction and Architectural Management, 9(3), 162-173. http://dx.doi.org/10.1046/j.1365232X.2002.00252.x

Dorst, K. (2003). Understanding design (p. 205). BIS.

Emmitt, S. (1999). Architectural management-an evolving field. Engineering Construction and Architectural Management, 6(2), 188-196. http://dx.doi.org/10.1046/j.1365-232x.1999.00108.x

Fan, S., Sia, C. L., \& Zhao, J. (2012). Towards Collaboration Virtualization Theory. PACIS 2012 Proceedings, $1-8$.

Fiol, C. M., \& O'Connor, E. J. (2005). Identification in Face-to-Face, Hybrid, and Pure Virtual Teams: Untangling the Contradictions. Organization Science, 16(1), 19-32. http://dx.doi.org/10.1287/orsc. 1040.0101

Fisher, T. (2000). In the Scheme of Things: Alternative Thinking on the Practice of Architecture (p. 155). U of Minnesota Press.

Frank Biocca, M. R. L. (1995). Communication in the Age of Virtual Reality (p. 401). L. Erlbaum Associates.

Frens, C. H. and J. (2008). Designing for the Unknown: A Design Process for the Future Generation of Highly Interactive Systems and Products. In E\&PDE 2008: Engineering and Product Design Education 2008.

Frost, P., \& Warren, P. (2000). Virtual reality used in a collaborative architectural design process. 2000 IEEE Conference on Information Visualization. An International Conference on Computer Visualization and Graphics, 568-573. http://dx.doi.org/10.1109/IV.2000.859814

Gabriel, G. C., \& Maher, M. L. (2002). Coding and modelling communication in architectural collaborative design. Automation in Construction, 11(2), 199-211. http://dx.doi.org/10.1016/S0926-5805(00)00098-4

Graell-Colas, M. (2009). Exploring Visual Means for Communication and Collaboration in Multidisciplinary Teams.

Gray, C., \& Hughes, W. (2001). Building Design Management (Vol. 66, p. 177). Butterworth-Heinemann.

Handy, C. (1999). Trust and the virtual organization (pp. 107-120).

Harold Dwight Lasswell. (1948). Communication Theory.

Johansen, R. (1988). GroupWare: Computer Support for Business Teams.

Egan, J. (1998). Rethinking construction.

John Restrepo, H. C. (2004). Problem Structuring and Information Access in Design.

Kalay, Y. E. (2004). Architecture's New Media: Principles, Theories, and Methods of Computer-aided Design (p. 536). MIT Press.

Kaptelinin, V. (1996). Context and Consciousness: Activity Theory and Human-computer Interaction (p. 400). MIT Press. 
Khee Poh Lam, N. H. W., \& F. H. (1999). A Study of the Use of Performance-Based Simulation Tools for Building Design and Evaluation in Singapore.

Krenk, C. (2006). The Communicational Aspects of the Building Process - A Necessary Expansion of the Scope. ... 2006-International Conference on Adaptable Building ..., (July), 25-30.

Lawson, B. (1997). How Designers Think: The Design Process Demystified (p. 318). Architectural Press.

Lawson, B., \& Loke, S. (1997). Computers, words and pictures. Design Studies, 18, 171-183. http://dx.doi.org/10.1016/S0142-694X(97)85459-2

Lee, Y. (2008). Design participation tactics: the challenges and new roles for designers in the co-design process. CoDesign, 4(1), 31-50. http://dx.doi.org/10.1080/15710880701875613

Licklider, J., \& Taylor, R. (1968). The computer as a communication device. Science and Technology (August). Retrieved from http://floridacom.org/wp-content/uploads/rsjp/attachments/9a4787d5cc7c4cba59743b771 a7979e0-2.pdf

Lyytinen, K., \& Hirschheim, R. (1988). Information systems failures-a survey and classification of the empirical literature (pp. 257-309). Oxford University Press, Inc.

Mahdavi, A. (2003). An Inquiry into the Building Performance Simulation Tools.

Maier, A. M., Kreimeyer, M., Hepperle, C., Eckert, C. M., Lindemann, U., \& Clarkson, P. J. (2008). Exploration of Correlations between Factors Influencing Communication in Complex Product Development. Concurrent Engineering, 16(1), 37-59. http://dx.doi.org/10.1177/1063293X07084638

Moum, A. (2008). Anita Moum Exploring Relations between the Architectural Design Process and ICT Learning from Practitioners 'Stories.

Norouzi, N., Shabak, M., Embi, M. R. Bin, \& Khan, T. H. (2014). Participation Problems and Communication Difficulties in Architectural Design Practice. Life Science Journal, 11(9), 984-990. Retrieved from http://www.lifesciencesite.com//sj//life1109/145_26195life110914_984_990.pdf

oann Keyton, P. S. Z. (2006). Case Studies for Organizational Communication: Understanding Communication Processes (p. 421). Roxbury Publishing Company.

Otter, A. Den, \& Emmitt, S. (2008). Design Team Communication and Design Task Complexity: The Preference for Dialogues. Architectural Engineering and Design Management, 4(2), 121-129. http://dx.doi.org/ 10.3763/aedm.2008.0072

Overby, E. (2008). Process Virtualization Theory and the Impact of Information Technology. Organization Science, 19(2), 277-291. http://dx.doi.org/10.1287/orsc.1070.0316

Overby, E. (2012). Information Systems Theory, 28, 107-124. http://dx.doi.org/10.1007/978-1-4419-6108-2

Oxman, R. (2008). Digital architecture as a challenge for design pedagogy: Theory, knowledge, models and medium. Design Studies, 29(2), 99-120. http://dx.doi.org/10.1016/j.destud.2007.12.003

RIBA. (2007). Taking Action (August).

Sarvarazadeh, S. K., Lamit, H., Norouzi, N., \& Shabak, M. (2013). The Existing Capacities for Citizen Participation in the Structural Transformations of the Historic Core of Shiraz. Life Science Journal, 10(2), 61-68.

Schnabel, M. (2007). From virtuality to reality and back. Proceedings of the ..., 1-15.

Schön, D. A. (1987). Educating the reflective practitioner: toward a new design for teaching and learning in the professions (p. 355). Jossey-Bass.

Schramm, W. L. (1955). Models of Communication.

Shabak, M., Norouzi, N., Abdullah, A. B. M., \& Khan, T. H. (2014). Evaluating common spaces in residential communities: An examination of the relationship between perceived environmental quality of place and residents' satisfaction. Life Science Journal, 11(11), 127-131.

Shabak, M., Norouzi, N., \& Khan, T. (2013). An Attempt to Measure the Success of Residential Common Space: A Case Study in Malaysia. International Proceedings of Economics ..., 56, 148.

Shen, W. (2011). A BIM-based Pre-occupancy Evaluation Platform (PEP) for facilitating designer-client communication in the early design stage. The Hong Kong Polytechnic University. Retrieved from http://repository.lib.polyu.edu.hk/jspui/handle/10397/5313 
Tareef Hayat Khan, A. S. bin A., \& M. A. A. S. K. (2012). Students' Learning Style in Architecture: A Case Study in UTM, Malaysia. In International Conference on Science, Technology and Social Sciences.

Weaver, W. (1949). Shannon and Weaver.

Weytjens, L., Verdonck, E., \& Verbeeck, G. (2009). Classification and use of design tools: The roles of tools in the architectural design process.

Wood, J. (2014). Communication in Our Lives (p. 480). Cengage Learning.

Yoo, Y., \& Alavi, M. (2004). Emergent leadership in virtual teams: What do emergent leaders do? Information and Organization, 14(1), 27-58. http://dx.doi.org/10.1016/j.infoandorg.2003.11.001

\section{Copyrights}

Copyright for this article is retained by the author(s), with first publication rights granted to the journal.

This is an open-access article distributed under the terms and conditions of the Creative Commons Attribution license (http://creativecommons.org/licenses/by/3.0/). 